\title{
Effects of different light sources on tooth shade selection
}

\section{Wpływ różnych źródeł światła na wybór odcienia koloru zęba}

\author{
Małgorzata Śmielecka ${ }^{\mathrm{A}-\mathrm{D}, \mathrm{F}}$, Barbara Dorocka-Bobkowska ${ }^{\mathrm{A}, \mathrm{E}, \mathrm{F}}$ \\ Department of Gerodontology and Oral Pathology, Poznan University of Medical Sciences, Poland \\ A - research concept and design; $\mathrm{B}$ - collection and/or assembly of data; $\mathrm{C}$ - data analysis and interpretation; \\ $D$ - writing the article; $E$ - critical revision of the article; $F$ - final approval of the article
}

Address for correspondence

Małgorzata Śmielecka

E-mail:malgosia.smielecka@gmail.com

Funding sources

None declared

Conflict of interest

None declared

Received on October 15, 2019

Reviewed on October 27, 2019

Accepted on November 8, 2019

Published online on February 18,2020

Cite as

Śmielecka M, Dorocka-Bobkowska B. Effects of different light sources on tooth shade selection. Dent Med Probl. 2020;57(1):61-66. doi:10.17219/dmp/114112

DOI

$10.17219 / \mathrm{dmp} / 114112$

Copyright

๑ 2020 by Wroclaw Medical University

This is an article distributed under the terms of the

Creative Commons Attribution 3.0 Unported License (CC BY 3.0)

(https://creativecommons.org/licenses/by/3.0/)

\begin{abstract}
Background. Differences in lighting conditions can make matching the shade of a single porcelain tooth to the natural adjacent teeth very challenging.

Objectives. The purpose of the study was to examine visual shade selection under 3 different light sources - natural daylight, a dental operating light and a color-corrected light.
\end{abstract}

Material and methods. The visual assessment was based on a comparison between a shade guide and the target tooth. One observer with normal color vision was asked to visually match the color of the maxillary central right incisor and the maxillary right canine in a group of 100 subjects, aged 22-40 years. Two shade guides were used - VITA Vitapan Classica ${ }^{\circledR}$ and VITA 3D Master ${ }^{\circledR}$ - in natural daylight as well as under an operating light and a handheld light (Demetron Shade Light ${ }^{\circledR}$ ). The VITA Easyshade ${ }^{\circledR}$ spectrophotometer was used to evaluate the results of the visual shade selection method.

Results. Significant differences were found between the effects of using the shade guide systems $(p<0.05)$ and light sources $(p<0.05)$. Overall, the use of the Vitapan Classical shade guide significantly improved the correlation between visual matching and the spectrophotometer readings.

Conclusions. Within the limitations of this study, the Vitapan Classical shade guide demonstrated superior agreement in shade selection as compared to the 3D Master shade guide. The Demetron Shade Light was proven to be a useful device for the color matching of artificial teeth in prosthodontic treatment. Visual tooth color matching is a subjective method and it produces the best results under a color-matching light.

Key words: color perception, light sources, shade guides, spectrophotometer, tooth color

Słowa kluczowe: postrzeganie kolorów, źródła światła, wzorniki kolorów, spektrofotometr, kolor zęba 


\section{Introduction}

Correct color evaluation and shade matching in prosthetic restorations is an important aspect of prosthetic treatment, which largely affects patient satisfaction. ${ }^{1}$ Tooth color is most often assessed visually with readymade shade guides provided by the manufacturers of dental products. ${ }^{2}$ However, the method is subjective, as color perception is affected by several parameters, e.g., shade, saturation, brightness, translucency, opalescence, reflectance, and fluorescence, ${ }^{3}$ as well as by the individual differences of the human eye and brain. ${ }^{4}$ Color perceived by the human eye may be distorted by lighting conditions, gingiva color and the colors of the surrounding environment. ${ }^{5}$ In order to improve the esthetic outcome of the treatment and choose the best tooth shade for the patient, a growing number of devices have been made available to assist dentists in optimizing the process of color evaluation and shade selection. Such aids for qualitative and quantitative color evaluation include digital cameras, colorimeters and spectrophotometers. Other noteworthy products include lamps specially designed for color matching.

Factors affecting artificial tooth shade matching include the source of light, the object observed and the observer. ${ }^{4}$ Three sources of light are available in a dental surgery: natural daylight, which is highly variable; the operating light of a dental unit, with a bias toward the red region of the visible spectrum as compared with natural sunlight; and finally, fluorescent ceiling lights, which - unlike incandescent lights - have various colorrendering properties depending on the specified color temperature. ${ }^{6}$ The optimal conditions for tooth shade matching are provided by a light having a color temperature between 5,500 $\mathrm{K}$ and 6,500 K, and the Color Rendering Index (CRI) greater than 90. When matching the shade of artificial teeth in prosthetics, one should perform the assessment in the presence of only 1 light source, as overlapping illumination from different sources may promote metamerism. ${ }^{6}$

The color of the natural teeth depends on the optical properties of the enamel and dentin. When light reaches the tooth surface, the following phenomena may be observed: light transmission; reflection; dispersion; and absorption. ${ }^{2}$ Translucency, opacity, opalescence, surface gloss, and fluorescence are secondary features to shade, saturation and brightness affecting the appearance of the teeth. ${ }^{3}$ The first 2 features are considered the most relevant, and they depend on the spectral distribution and quantity of the reflected light. ${ }^{7}$ The teeth are most translucent at the incisal edges, decreasing toward the center, with the lowest translucency in the cervical area. ${ }^{8}$ The enamel of the natural tooth is responsible for opalescence and its translucency causes the scintillation of shortwavelength light, resulting in blue-grey reflexes, easily noticeable at the incisal edge. ${ }^{9}$ Opalescence promotes the rainbow effect, and depends on the direction and location of the lighting around the tooth as well as on the dispersion, diffraction and interference of light waves. ${ }^{3}$ The shade of the teeth is mainly due to the color of the dentin. ${ }^{10}$ After penetrating the enamel, UV rays reach the dentin and cause fluorescence, ranging from intense white to light blue color. ${ }^{9}$ When surrounded by a cofferdam for $20 \mathrm{~min}$, the dry teeth appear whiter, but regain their natural color 15 min after the removal of the cofferdam. ${ }^{11}$ Similarly, the teeth appear whiter for half an hour after impressions are taken with polyvinyl siloxane (PVS). ${ }^{11}$ Therefore, it is very important to match the shade of the teeth prior to performing any procedures that would dry them. ${ }^{12}$ Furthermore, the morphology of the tooth surface affects the amount and color of the reflected light; an uneven or rough surface results in a greater dispersion of light as compared to a smooth surface. Thus, the amount of the light reflected from the surface of the enamel increases immediately after the teeth are brushed. ${ }^{13}$ Moreover, the effect of contrast creates optical illusions and affects the perceived brightness of the teeth. The surrounding colors, such as the skin tone, the color of the eyes, adjacent teeth, lips, and gingivae, will also change the perception of tooth color. ${ }^{5}$ Darker surroundings will cause the teeth to look brighter. When assessing the shade, a bright background should not be placed behind the observed teeth, as the dark oral cavity absorbs light. ${ }^{14}$ It is also important to remember that the teeth observed in close proximity appear bigger, and therefore brighter. Prosthodontists color match the teeth in a more precise manner than general dental practitioners. Education and training in color matching affect the selection of the optimal shade. ${ }^{15}$

The purpose of this study was to examine visual shade selection under 3 different light sources - natural daylight, operating light and corrected light.

\section{Material and methods}

One hundred participants (22 males and 78 females) were recruited for this study. The age of the patients ranged from 22 to 40 years (mean age: $25.11 \pm 3.24$ years). Each participant was provided with a full explanation of the study and the procedures to be followed. The participants' written informed consent was obtained before they were enrolled in the study.

The study was approved by the Ethics Committee of Poznan University of Medical Sciences in Poland.

The visual assessment was based on a comparison between 2 shade guides and the target tooth. One observer with normal color vision was asked to visually match the color of the maxillary central right incisor and the maxillary right canine in a group of 100 subjects. 
Two shade guides were used - VITA Vitapan Classical ${ }^{\circledR}$ and VITA 3D Master ${ }^{\circledR}$ (VITA Zahnfabrik H. Rauter GmbH \& Co. KG, Bad Säckingen, Germany). The assessment was performed under 3 lighting conditions: in natural daylight - all measurements were carried out on 1 dental chair located by the window facing north, on a partly cloudy day before noon; using the operating light KAVOLUX ${ }^{\circledR} 1410 \mathrm{C}$ (Kaltenbach \& Voigt GmbH \& Co. KG, Biberach an der Riß, Germany); and using a handheld light specially designed for color matching in dentistry - Demetron Shade Light ${ }^{\circledR}$ (Kerr Corporation, Orange, USA). The results were then re-evaluated with the use of the VITA Easyshade ${ }^{\circledR}$ spectrophotometer (VITA Zahnfabrik H. Rauter GmbH \& Co. KG).

The inclusion criteria required: live, healthy maxillary central right incisors and maxillary right canines with no cracks, fillings and/or discolorations. The exclusion criteria comprised the following: dead teeth with discolorations, fillings and after whitening procedures.

The statistical analysis was performed with Statistica PL, v. 12.0 (StatSoft Polska Sp. z o.o., Cracow, Poland). All comparisons between daylight, the operating light, the Demetron light, the Vitapan Classical shade guide, and the 3D Master guide were carried out with a test for differences between 2 structure indicators. The results were deemed statistically significant at $p<0.05$.

\section{Results}

The agreement differed significantly between the types of lighting conditions. Under the Demetron light, an agreement of $69 \%$ was obtained for the maxillary right central incisors with respect to the Vitapan Classical guide and 33\% when using the 3D Master guide; these scores were significantly higher $(p<0.05)$ than those obtained with daylight and the operating light for both shade guides. The use of the Demetron light also resulted in the highest agreement for the canines - 73\% in the case of the Vitapan Classical guide and 33\% for the 3D Master guide. These results are shown in Fig. 1.

A significant difference was evident between the Vitapan Classical and 3D Master shade guides in incisor color matching compatibility according to the dentist's assessment and the Easyshade spectrophotometer measurements $(p<0.05)$, with the 3D Master shade guide showing a statistically significantly lower agreement. The results of incisor color matching compatibility for the assessments made by the dentist under 3 different lighting conditions and the selection based on the Easyshade spectrophotometer for the Vitapan Classical and 3D Master shade guides are presented in Table 1.

A comparative analysis demonstrated a significant difference between the Vitapan Classical and 3D Master shade guides in canine color matching compatibility when the measurements were performed by the dentist in daylight and with the Easyshade spectrophotometer $(p<0.05)$. A significant difference was found between the Vitapan Classical and 3D Master shade guides in canine color matching compatibility when the measurements were performed by the dentist under the operating light and with the Easyshade spectrophotometer $(p<0.05)$. The 3D Master guide showed a poorer agreement in canine color measurements carried out by the dentist with the Demetron light and by means of the Easyshade spectrophotometer $(p<0.05)$. These results are summarized in Table 2.

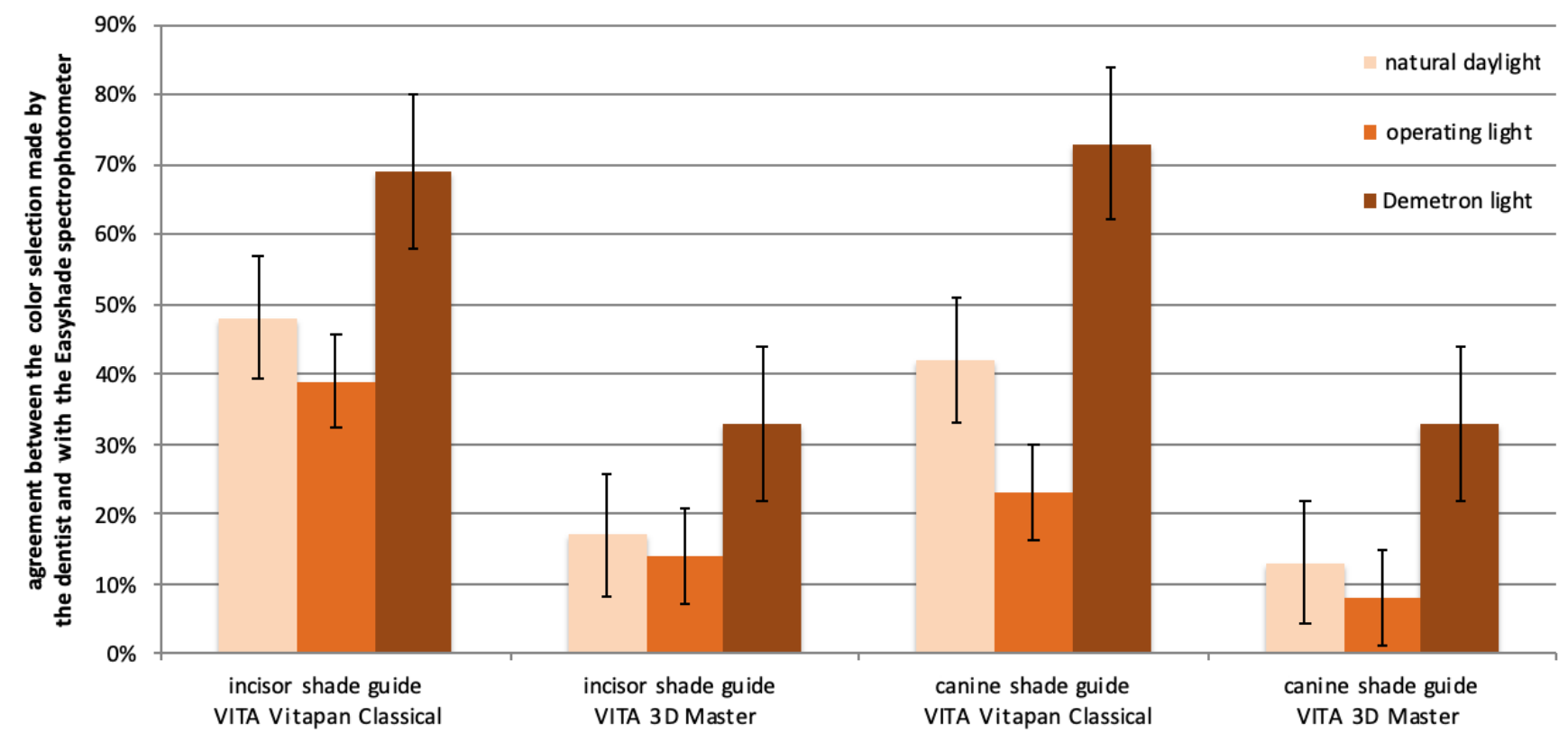

Fig. 1. Percentage of the compatibility of the colors chosen by the dentist and with the Easyshade device under different light sources Data presented as mean \pm standard deviation (SD). 
Table 1. Compatibility of the Easyshade measurements with the dentist's selection under different lighting conditions for the incisors

\begin{tabular}{|c|c|c|c|c|c|c|}
\hline \multirow{2}{*}{ Compatibility } & \multirow{2}{*}{ Daylight } & \multirow{2}{*}{$\begin{array}{l}\text { Operating } \\
\text { light }\end{array}$} & \multirow{2}{*}{ Demetron } & \multicolumn{3}{|c|}{$p$-value } \\
\hline & & & & daylight vs operating light & daylight vs Demetron & operating light vs Demetron \\
\hline $\begin{array}{l}\text { Agreement of Easyshade } \\
\text { Vitapan Classical } \\
\text { with Vitapan Classical [\%] } \\
(\mathrm{N}=100)\end{array}$ & 48 & 39 & 69 & 0.1993 & 0.0002 & 0.0001 \\
\hline $\begin{array}{l}\text { Agreement of Easyshade } \\
\text { 3D Master } \\
\text { with 3D Master [\%] } \\
(\mathrm{N}=100)\end{array}$ & 14 & 17 & 33 & 0.5578 & 0.0015 & 0.0090 \\
\hline$p$-value & 0.0001 & 0.0005 & 0.0001 & - & - & - \\
\hline
\end{tabular}

Table 2. Compatibility of the Easyshade measurements with the dentist's selection under different lighting conditions for the canines

\begin{tabular}{|c|c|c|c|c|c|c|}
\hline \multirow{2}{*}{ Compatibility } & \multirow{2}{*}{ Daylight } & \multirow{2}{*}{$\begin{array}{l}\text { Operating } \\
\text { light }\end{array}$} & \multirow{2}{*}{ Demetron } & \multicolumn{3}{|c|}{$p$-value } \\
\hline & & & & daylight vs operating light & daylight vs Demetron & operating light vs Demetron \\
\hline $\begin{array}{l}\text { Agreement of Easyshade } \\
\text { Vitapan Classical } \\
\text { with Vitapan Classical [\%] } \\
(\mathrm{N}=100)\end{array}$ & 42 & 23 & 73 & 0.0041 & 0.0001 & 0.0001 \\
\hline $\begin{array}{l}\text { Agreement of Easyshade } \\
\text { 3D Master } \\
\text { with 3D Master [\%] } \\
(\mathrm{N}=100)\end{array}$ & 13 & 8 & 33 & 0.2488 & 0.0003 & 0.0001 \\
\hline$p$-value & 0.0001 & 0.0005 & 0.0001 & - & - & - \\
\hline
\end{tabular}

\section{Discussion}

The visual method of artificial tooth shade matching using a standard shade guide is the most commonly used method in dentistry. ${ }^{16}$ The human eye can successfully distinguish even slight differences in color. ${ }^{17}$ However, the visual assessment of tooth color is considered imperfect. ${ }^{18}$ Variations have been observed in the shades selected by different observers as well as in the case of a single observer matching the shade for the same tooth on different occasions. ${ }^{19}$

Shade matching should be performed in adequate lighting conditions; however, it is difficult to ensure them in everyday dental practice. Our research demonstrated inconsistencies in the tooth shade selection made by a single dentist. The same incisal shade according to the Vitapan Classical shade guide examined under 3 different light sources was selected in only 29 cases in a sample of 100 patients and in nearly 50 cases (47\% of the study population) when the 3D Master shade guide was used. Canine shade matching compatibility was also low, accounting for only $30 \%$ for both shade guides. The research confirmed the thesis that the visual method of artificial tooth color matching is inconsistent. The results demonstrated a significant influence of illumination on color perception. The color temperature of natural daylight ranges from $1,000 \mathrm{~K}$ to $20,000 \mathrm{~K}^{20}$; therefore, such a light source may not be adequate for tooth color matching. ${ }^{4}$ A surgery operating light may also affect color perception. ${ }^{6}$ However, lighting systems dedicated to tooth color evaluation promote accurate shade selection when using a guide. ${ }^{21}$ The Demetron Shade Light used to illuminate the teeth emits white light, which simulates the northern hemisphere daylight of $6,500 \mathrm{~K}$. This color temperature is the most suitable for color evaluation according to a previous study. ${ }^{22}$ The Demetron light is held at a distance of $5-7.5 \mathrm{~cm}$ from the inspected teeth, with the shade guide nearby. Observations are made through a specially designed, small window. Our research determined that during subjective evaluation, the highest compatibility of the color assessment for incisors was obtained in daylight with the Demetron light, whereas the lowest was found when daylight was combined with the operating light using the Vitapan Classical shade guide. The 3D Master shade guide also demonstrated good compatibility in daylight with the Demetron light. However, no statistically significant difference was found in the case of other compatibility measurements with respect to color matching dependence on the light source used. Similar results were obtained when both shade guides were compared in daylight and using the Demetron light, with 59\% and 63\% compatibility for the Vitapan Classical guide and the 3D Master guide, respectively. Observations made in the current study suggest that dentists tend to choose brighter samples from a guide when using an operating light. When the subjective and objective tooth color matching methods were compared, the colors chosen by the dentist using the Demetron light showed the highest compatibility. In the case of the incisors, color matching compatibility occurred in 
$69 \%$ of cases using the Vitapan Classical shade guide and in $33 \%$ of cases using the 3D Master guide. Likewise, in the case of the canines, it accounted for $73 \%$ of the measurements made with the Vitaplan Classical guide and $33 \%$ when using the 3D Master guide. A study which compared the effects of 2 light sources - daylight and the color-corrected Demetron light - on tooth color matching compatibility, performed by dentistry students, found a greater compatibility using the Demetron light as compared to daylight only. ${ }^{23}$ The advantage of using this light source in tooth color matching carried out by students was also observed in later studies. ${ }^{24}$ The device, emitting light of 5,500-6,500 $\mathrm{K}$ and 1,000 Lx, and CRI exceeding 90, has optimized lighting conditions; however, the task of selecting tooth color continues to be the responsibility of the prosthodontist and depends on factors like the observer's age, gender, vision defects, experience, fatigue, and emotional state. ${ }^{15}$ The dentist's knowledge of shade selection plays an important role in ensuring accurate measurements. Research by other authors indicates a need to improve the qualifications of the dental care team through courses and training covering this topic. ${ }^{21,23}$ For a number of years studies have been underway to develop an ideal, objective measuring device, which would eliminate all the abovementioned flaws of shade selection. Our research showed a greater compatibility in the color assessment of the incisors and canines when using the $\mathrm{Vi}$ tapan Classical shade guide as compared to the 3D Master shade guide. Most reported studies indicated a higher compatibility of the measurements carried out with the Vitapan Classical shade guide with the use of different spectrophotometric and colorimetric devices as compared to the 3D Master shade guide. ${ }^{19,25}$

The 3D Master shade guide was introduced into the market in the 1990s and was supposed to cover all of the natural tooth shades. The system is recommended by the American Dental Association and considered by some authors as the optimal shade guide for assessing tooth color, with fewer errors in the spatial distribution of colors as compared to the Vitapan Classical shade guide. ${ }^{26,27}$ Lee et al. decided to verify the differences in the distribution of brightness and saturation between the adjacent samples of the 3D Master shade guide with a spectroradiometer. ${ }^{28}$ The authors believed that the differences between the individual guide colors were irregular. ${ }^{28}$ The manufacturer of the 3D Master guide recommends a 3-step methodology when matching tooth color. First, a sample is chosen from one of the 5 brightness groups. Next, saturation is selected, and finally a shade is chosen. However, previous studies demonstrated that samples of a single group did not belong to the same brightness group at all. ${ }^{29}$ Our research indicated that it was often the case that during color matching, 2 samples from 2 different brightness groups were most similar to the natural tooth shade, which may have resulted in low compatibility between the selected colors and the spectrophotometer readings. Additionally, a lower compatibility of the dentist's choice and the selection made with the Easyshade spectrophotometer for the 3D Master shade guide may be due to the intermediate tones, which are not included among the 26 guide samples, whereas the spectrophotometer does not encounter this problem. ${ }^{28}$ Apart from that, the compatibility rate may significantly differ with respect to the color-measuring devices and the type of teeth evaluated..$^{30}$ Regardless of lighting conditions, the compatibility of the Easyshade device measurements with the selection made by the dentist was always higher in the case of the Vitapan Classical shade guide for both the incisors and canines.

\section{Conclusions}

This study showed that the VITA Vitapan Classical system demonstrated superior compatibility in shade selection as compared to the VITA 3D Master system. Visual tooth color matching is a subjective method, dependent on lighting conditions. The Demetron Shade Light was found to be a useful device for the color matching of artificial teeth in prosthodontic treatment.

\section{ORCID iDs}

Małgorzata Śmielecka (D) https://orcid.org/0000-0002-2199-1961

Barbara Dorocka-Bobkowska (D) https://orcid.org/0000-0003-3659-7761

\section{References}

1. Okuda WH. Minimally invasive dentistry and its impact on esthetic restorative dentistry. Gen Dent. 2013;61(5):24-26.

2. van der Burgt TP, ten Bosch JJ, Borsboom PC, Kortsmit WJ. A comparison of new and conventional methods for quantification of tooth color. J Prosthet Dent. 1990;63(2):155-162.

3. Terry DA, Geller W, Tric O, Anderson MJ, Tourville M, Kobashigawa A. Anatomical form defines color: Function, form, and aesthetics. Pract Proced Aesthet Dent. 2002;14(1):59-68.

4. Joiner A. Tooth colour: A review of the literature. J Dent. 2004;32(Suppl 1):3-12.

5. Reno EA, Sunberg RJ, Block RP, Bush RD. The influence of lip/gum color on subject perception of tooth color. J Dent Res. 2000;79:381.

6. Sproull RC. Color matching in dentistry. Part I. The three-dimensional nature of color. 1973. J Prosthet Dent. 2001;86(5):453-457.

7. Winter R. Visualizing the natural dentition. J Esthet Dent. 1993;5(3):102-117.

8. Hasegawa A, Ikeda I, Kawaguchi S. Color and translucency of in vivo natural central incisors. J Prosthet Dent. 2000; 83(4):418-423.

9. Vanini L. Light and color in anterior composite restorations. Pract Periodontics Aesthet Dent. 1996;8(7):673-682;quiz 684.

10. ten Bosch JJ, Coops JC. Tooth color and reflectance as related to light scattering and enamel hardness. J Dent Res. 1995;74(1):374-380.

11. Russell MD, Gulfraz M, Moss BW. In vivo measurement of colour changes in natural teeth. J Oral Rehabil. 2000;27(9):786-792.

12. Burki Z, Watkins S, Wilson R, Fenlon M. A randomized controlled trial to investigate the effects of dehydration on tooth colour. J Dent. 2013;41(3):250-257.

13. Redmalm G, Johannsen $G$, Rydén $H$. Lustre changes on teeth. The use of laser light for reflexion measurements on the tooth surface - in vivo. Swed Dent J. 1985;9(1):29-35.

14. Lee YK, Lim BS, Kim CW. Difference in the colour and colour change of dental resin composites by the background. J Oral Rehabil. 2005;32(3):227-233. 
15. Milagres V, Teixeira ML, Miranda ME, Osorio Silva CH, Ribeiro Pinto JR Effect of gender, experience, and value on color perception. Oper Dent. 2012;37(3):228-233.

16. Jarad FD, Russell MD, Moss BW. The use of digital imaging for colour matching and communication in restorative dentistry. $\mathrm{Br}$ Dent J. 2005;199(1):43-49;discussion 33.

17. Paul S, Peter A, Pietroban N, Hämmerle CH. Visual and spectrophotometric shade analysis of human teeth. J Dent Res. 2002;81(8):578-582.

18. Horn DJ, Bulan-Brady J, Hicks ML. Sphere spectrophotometer versus human evaluation of tooth shade. J Endod. 1998;24(12):786-790.

19. Fani G, Vichi A, Davidson CL. Spectrophotometric and visual shade measurements of human teeth using three shade guides. Am J Dent. 2007;20(3):142-146.

20. Saleski CG. Color, light and shade matching. J Prosthet Dent. 1972;27(3):263-268.

21. Clary JA, Ontiveros JC, Cron SG, Paravina RD. Influence of light source, polarization, education, and training on shade matching quality. J Prosthet Dent. 2016;116(1):91-97.

22. Romnay KA, Indow T. A model for the simultaneous analysis of reflectance spectra and basis factors of Munsell color samples under D65 illumination in three-dimensional Euclidean space. Proc Natl Acad Sci U S A. 2002;99(17):11543-11546.

23. Curd FM, Jasinevicius TR, Graves A, Cox V, Sadan A. Comparison of the shade matching ability of dental students using two light sources. J Prosthet Dent. 2006;96(6):391-396.

24. Gasparik C, Grecu AG, Culic B, Badea ME, Dudea D. Shade-matching performance using a new light-correcting device. J Esthet Restor Dent. 2015;27(5):285-292.

25. Lagouvardos PE, Fougia AG, Diamantopoulou SA, Polyzois GL. Repeatability and interdevice reliability of two portable color selection devices in matching and measuring tooth color. $J$ Prosthet Dent. 2009;101(1):40-45.

26. Tsiliagkou A, Diamantopoulou S, Papazoglou E, Kakaboura A. Evaluation of reliability and validity of three dental color-matching devices. Int J Esthet Dent. 2016;11(1):110-124.

27. Liu M, Chen L, Liu X, Yang Y, Zheng M, Tan J. Online colour training system for dental students: A comprehensive assessment of different training protocols. J Oral Rehabil. 2015;42(4):282-290.

28. Lee YK, Yu B, Lim HN. Lightness, chroma, and hue distributions of a shade guide as measured by a spectroradiometer. J Prosthet Dent. 2010;104(3):173-181.

29. Gómez-Polo C, Gómez-Polo M, Martínez Vázquez De Parga JA, Celemín-Viñuela A. Study of the shade tabs of the toothguide 3D master through cluster analysis. Color Res Appl. 2015;40(2):194-200.

30. Igiel C, Weyhrauch $M$, Wentaschek $S$, Scheller H, Lehmann KM. Dental color matching: A comparison between visual and instrumental methods. Dent Mater J. 2016;35(1):63-69. 